\title{
Annotation
}

\section{BIOCHEMICAL ABNORMALITIES IN CHRONIC ERYTHRAEMIC MYELOSIS}

For a number of years, considerable interest and much investigation has been directed at a group of disorders characterized by refractory macrocytic anaemia, monocytosis, leukopenia, megaloblastoid erythroid hyperplasia of the bone marrow, ineffective erythropoiesis with increased serum iron and decreased plasma iron turnover, and in some instances transformation into acute myeloblastic or myelomonocytic leukaemia. Nomenclature for this group of disorders has varied according to the investigators.

Historically, Copelli (Copelli, 19 I2) and subsequently DiGuglielmo (DiGuglielmo, I923, 1926, 1928) described the first accounts of neoplastic erythroid disorders. Today, we recognize these as acute erythraemic myelosis, a rare and almost exclusively erythroid disorder that may be a transitory stage in the evolution of acute myeloblastic leukaemia (Gunz \& Baikie, 1974; Kass \& Schnitzer, 1975). Cytochemically, specific esterase granules characteristic of cells of granulocytic origin (Yam ct al, 197I) have been found in erythroid precursors from patients with acutc erythraemic myelosis (Kass, 1975a) and erythroleukaemia (Kass, 1976). These findings suggest that the abnormal erythroid precursors found in these two disorders possess properties of granulocytes, and that perhaps these neoplastic erythroid cells may originate from a common myeloblastic stem cell as has been shown in erythroblasts from patients with chronic erythroleukaemia (McClure et al, r965), chronic granulocytic leukaemia (Rastrick et al, 1968), and 'preleukaemia' (Dörmer et al, 1976).

Following the more precise description of acute erythraemic myelosis by DiGuglielmo in 1928, descriptions of other erythroid disorders characterized by anaemia refractory to haematinics available at the time began to appear. The concept of iron-loading anaemias was introduced by Israels and Wilkinson who called these types of anaemias 'achrestic' (Israels \& Wilkinson, 1936). Shortly after the description of achrestic anaemias, it was recognized that there may be a chronic form of erythraemic myelosis (Benedetti, 1939; Duesberg, 1940; Hcilmeyer \& Schöner, 194I; DiGuglielmo \& Quattrin, 1942).

The idea of a chronic type of erythraemic myelosis appeared to lie dormant for several years following its initial description. Subsequently, reports by several investigators detailed a primary acquired refractory anaemia characterized by increased iron stores and a hallmark of these types of anaemias, the ringed sideroblast (Dacic \& Mollin, I966; Bessis, I973). Various names were given to these entities, including chronic refractory anaemia with sideroblastic bone marrow (Björkman, I956), refractory normoblastic anaemia (Dacie et al, I959), and refractory sideroblastic anaemia (Heilmeyer et al, 1958).

In the late 1950 Dameshek attempted to unify these apparent divergent entities by suggesting that they all had common characteristics, including refractory macrocytic anaemia, splenomegaly, megaloblastoid erythroid hyperplasia with increased iron stores, and in some instances transformation into acute leukaemia. He suggested that the term 'DiGuglielmo syndrome' (Dameshek \& Baldini, 1958; Dameshek, 1965, 1969) be used to designate this group of crythroid disorders that seemed to be closely related. These included acute and

Correspondence: Dr Lawrence Kass, Department of Internal Medicine (Simpson Memorial Institute), The University of Michigan, Ann Arbor, Michigan 48109, U.S.A. 
chronic erythraemic myelosis (CEM), erythroleukaemia, and refractory sideroblastic anaemia.

Although conceptually imaginative and perhaps nosologically useful, Dameshek's classification causes confusion in an area already murky with bewildering nomenclature. As various individuals have pointed out (Dacie et al, 1959; Kushner et al, I97I), primary acquired refractory sideroblastic anaemia in its pure form as originally defined (Dacie et al, 1959) probably does not fit within the framework of the DiGuglielmo syndrome and consequently should not be equated with CEM. The two disorders differ substantially. In 'pure' refractory sideroblastic anaemia, large numbers of ringed sideroblasts are usually present in the marrow, and transformation into acute leukaemia does not occur. By contrast, CEM more properly belongs in a myeloproliferative category, in which the panmyelotic disturbances are often manifested by pseudo-Pelger Huet formation in polymorphonuclear leucocytes, reduced leucocyte alkaline phosphatase, elevated muramidase levels, peripheral monocytosis, and transformation into acute leukaemia. Sideroblastosis can be variable. 'Preleukaemia' (Saarni \& Linman, 1973), CEM without sideroblastosis, and refractory anaemia with myeloblastosis referred to by some as smouldering acute leukaemia or subacute granulocytic leukaemia, are probably also part of a spectrum that includes CEM, since patients who have these disorders have an increased propensity to develop myeloblastic or myelomonocytic leukaemia.

Of the entities included in the term DiGuglielmo syndrome, CEM is probably the most common. It is a disorder that usually affects older individuals, is frequently misdiagnosed and treated as though it were pernicious anaemia, probably because of the macrocytosis and marrow erythroid hyperplasia, but does not respond to conventional preparations of vitamin $B_{12}$. Monocytosis, leucopenia, and thrombocytopenia are frequently observed.

In typical cases of CEM the marrow is hypercellular with a characteristic type of megaloblastoid erythroid hyperplasia. In some instances up to $95 \%$ of the marrow cells are erythroid precursors. Proerythroblasts are increased and there are numerous aberrant-appearing intermediate and late megaloblastoid macronormoblasts with basophilic stippling and unusual shaped nuclei. Sideroblastosis and PAS (periodic acid-Schiff) positivity of erythroblasts are common but not invariable findings and may be minimal or at times substantial. Gigantism of erythroid precursors is frequently observed. Occasional patients show a modest rise in haemoglobin when treated with pharmacologic doses of folate, folinic acid, pyridoxine, and androgens either alone or in various combinations.

In a small number (approximately $3-5 \%$ ) of patients with CEM, acute myeloblastic, subacute myelomonocytic (Sexauer et al, I974), acute myelomonocytic, or erythroleukaemia will occur (Gunz \& Baikie, I974; Kass \& Schnitzer, 1975). At times the leukaemic transformation will be insidious. In other instances it appears to be blatant.

Recently, a number of studies have been reported that may help to shed light on some of the biochemical abnormalities involved in CEM. Abnormalities of nucleic acid synthesis (Wickramasinghe et al, I968) and in the type and composition of basic nucleoproteins (Kass, 1972, I973a, I974a, b) have been reported in this disorder. DNA synthesis is arrested, leading to intramedullary cell death (Wickramasinghe $e t$ al, 1968). Histones, basic nucleoprotein responsible for binding DNA into compact masses of chromatin, have also been found to be abnormal. An initial cytochemical study employed the ammoniacal silver reagent. This stain distinguishes between arginine-rich histone which stains brown to black, and lysinerich histone which stains yellow (Black \& Ansley, I965). In nuclei of erythroid precursors 
from marrows of patients with CEM, the ammoniacal silver stain revealed a punctate black speckling believed to represent deposits of arginine-rich histone (Kass, 1972). Among erythroid precursors from anaemic patients including those with vitamin $B_{12}$ or folate deficiency and normal individuals, this type of black punctate speckling was observed only in erythroid precursors of thrombotic thrombocytopenic purpura (Kass, 1973b).

Histones extracted from nuclei of CEM crythroid precursors exlibited a unique pattern on polyacrylamide disc electrophoresis when stained with alkaline Fast green at $\mathrm{pH} 9.0$ (Kass, 1973a). Hydrolysis of arginine-rich histone fractions followed by high voltage electrophoresis revcaled methylated arginines (Kass, I974a). Only $\mathrm{N}^{\mathrm{G}}$-dimethyl and $\mathrm{N}^{\mathrm{G}} \mathrm{N}^{\prime} \mathrm{G}$-dimethyl-1arginine were detcctable. Methylated arginines were not observed in hydrolysates of histones cxtracted from erythroid precursors in various other kinds of anaemias, including nutritional megaloblastic anaemias, although they may have been present in amounts too small to be detected by the methods used.

Presumptive cytochemical evidence for the presence of methylated arginines in the nuclei of CEM erythroid precursors was also obtained. After removal of nucleic acids, the thiazine dye azure A stained nuclei of CEM erythroid precursors metachromatically (Kass, 1974b). Test tube experiments utilizing a wide variety of biological substances suggested that the metachromasia was due to methylated arginines, yet it is certainly possible that other as yet untested and perhaps unknown substances may give a similar reaction with azure A.

Ultrastructural evidence for abnormalities of histones has also been reported. In erythroid precursors stained with the ammoniacal silver reagent, dense deposits of silver representing sites of arginine-rich histone were found predominantly in areas of heterochromatin, or metabolically repressed DNA (Kass \& Gray, 1975). These findings suggest that arginine-rich histones occur in excessive amounts in CEM compared to normal, and because of their binding to DNA may influence the process of gene readout. At this point, relationships that may exist between the apparent intimate association of arginine-rich histone with metabolically repressed DNA and subsequent leukaemic transformation are not understood.

Abnormalities of various cytoplasmic constituents have been identified in erythroblasts in CEM. Among the first of these to be reported were abnormalities in the metabolism and storage of iron in the form of ferritin. In CEM, coarse granules representing iron within the cristae and lamellae of mitochondria can be seen surrounding the nucleus of erythroid precursors, particularly early and late megaloblastoid intermediate macronormoblasts. These cells have been called ringed sideroblasts (Bessis, 1973) and have been considered as one of several important diagnostic criteria for CEM (Kass \& Schnitzer, 1975). The presence of only a few sideroblasts, however, does not necessarily exclude the diagnosis of CEM. Recently, a rapid test for the demonstration of ringed sideroblasts using the anthraquinone dye alizarine Red $S$ was developed (Kass, 1975b). This stain produces a purple perinuclear halo and purple granules in erythroblasts that contain coarse deposits of ferritin using conventional Prussian blue staining. Presumably, ferritin reacts with the alizarine dye to produce the purple colour.

Metabolism of glycogen is abnormal in erythroblasts from patients with CEM. Increased deposits of glycogen detectable by the PAS reagent are found in many of the erythroid precursors (Quaglino \& Hayhoe, 1960) in some patients and in few or none of the erythroblasts in others. Mechanisms responsible for increased deposits of glycogen are as yet unclear, but may relate to abnormalities in glycogen catabolism in these cells. Normally, amylophos- 
phorylase acts to degrade glycogen (Swanson, 1974). Recent evidence has shown that under certain presumably abnormal conditions, the reaction may act to favour biosynthesis rather than degradation of glycogen (Swanson, 1974). Cytochemically, increased amounts of phosphorylase found in erythroid precursors from patients with CEM may constitute evidence for reversibility of this reaction, and may explain in part the increased deposits of glycogen detectable by the PAS reagent (Kass \& Hadi, 1975).

Activities of various enzymes have been studied in CEM. Several investigators have demonstrated that activity of pyruvic kinase is decreased in CEM erythrocytes (Bessis et al, I969; Valentine et al, 1973). Erythrocyte delta-amino laevulinic acid synthetase and haem synthetase levels are also decreased (Steiner $e t a l, 1963)$. However, other reports have indicated that haem synthetase levels are normal in CEM (Vavra \& Poff, 1967; Kushner $e t$ al, 1971). Additional aspects of haemoglobin synthesis may be abnormal in CEM, and decreased levels of erythrocyte protoporphyrin (Kushner et al, 197I) and decreased synthesis of haemoglobin (Necheles \& Dameshek, 1967) have been described.

Activity of nonspecific esterase is increased in CEM erythroid precursors, as it is in megaloblasts from patients with untreated pernicious anaemia (Rozenszajn et al, 1968). Cytochemically, nonspecific esterase using alpha naphthyl acetate as substrate is fluoride-sensitive in CEM (Kass \& Peters, I976) as is monocytic nonspecific esterase (Fisher \& Schmalzl, 1964). Electrophoresis of sonicates of marrows from patients with untreated iron deficiency anaemia, severe pernicious anaemia, and CEM in polyacrylamide gel followed by staining for nonspecific esterase using alpha naphthyl acetate as substrate demonstrated that three bands werc present in all of the conditions studied. All the esterase bands were fluoride-sensitive (Kass \& Peters, 1976). These findings are consistent with the interpretation that the intense nonspecific esterase activity observed in erythroid precursors in pernicious anaemia and in CEM is fluoride-sensitive, as is monocytic nonspecific esterase. However, further experiments will bc necessary to determine whether the predominantly erythroid nonspecific esterases can be distinguished from monocytic nonspecific esterase in terms of other properties, such as specificity for substrates other than alpha naphthyl acetate.

Activity of 5-methyltetrahydrofolate-homocysteine cobalamin methyltransferase was initially reported to be substantially lower in homogenates of marrows from patients with CEM than in marrows from patients with autoimmune haemolytic anaemia (Kass \& Boroush, 1976). More recent information using refined techniques and different patients indicated that activity of vitamin $B_{12}$ methyltransferase is as much as three to four times higher in sonicatcs of marrows obtained from patients with CEM than in normal marrow sonicates (Kass et al, 1976). Also, in marrows from patients with CEM, enzymatic activity is unresponsive to addition of methylcobalamin, as is the case with normal marrows. This finding contrasts to that observed in marrows obtained from patients with untreated pernicious anaemia. In this disorder, vitamin $B_{12}$ methyltransferase exists primarily as the apoenzyme (Taylor ot al, 1974), and its activity increases markedly after the addition of methylcobalamin, reflecting saturation of apoenzyme with its cofactor and formation of active vitamin $B_{12}$ holomethyltransferase.

The marked increase in vitamin $B_{12}$ methyltransferase activity in CEM is of interest and may relate to several factors. These include the predominantly erythroid character of the marrow (Schnitzer \& Kass, I973; Kass \& Schnitzer, 1975), high proliferative potential (Sauer 
of al, 1973) and intramedullary cell death found in CEM, and the possibility that this high enzymatic activity may be yet another reflection of the potentially neoplastic nature of the crythroid cells in CEM. Increased vitamin $\mathrm{B}_{12}$ methyltransferase activity may also relate to the cellular composition of the marrow, although as yet it has not been determined that procrythroblasts which predominate in CEM have higher activity of vitamin $B_{12}$ methyltransferase than more mature erythroblasts.

Elevated levels of vitamin $B_{12}$ methyltransferase may explain in part the refractoriness to treatment with conventional vitamin $\mathrm{B}_{12}$ preparations in this disorder. Addition of methylcobalamin to CEM marrow sonicates did not increase the enzymatic activity significantly, implying that the cnzyme cxists as the holomethyltransferase rather than the apoenzyme as in the case of pernicious anaemia where vitamin $B_{12}$ is a specific and effective therapeutic modality.

Factors leading to production of methylated arginines in histones extracted from crythroid precursors in CEM may also have a basis in cnzymatic abnormalities. Arginine-rich and perhaps methylated argininc-rich histones arc synthesized within the cytoplasm of cells on polysomes (Robbins \& Borun, 1967). Histonases, neutral proteases that degrade histones, may be abnormal or reduced in activity in CEM causing accumulation of arginine-rich and methylated arginine-rich histones (Kass \& Schnitzer, 1974; Kass, 1974c).

A second enzyme that may play a role in the formation of methylated arginines is the S-adenosylmethionine dependent arginine methyltransferase (Kaye \& Sheratzky, I969; Paik \& Kim, 1969; Baxter \& Byvoet, 1974). This enzyme catalyses the formation of methylated arginines by transfer of methyl groups to the guanidino group of arginine. Among various biological substances tested (Kaye \& Sheratzky, 1969; Paik \& Kim, 1969), arginine contained in histones appears to be preferentially methylated. In preliminary studies, activity of this enzyme was substantially higher in marrows from patients with CEM than in normal marrows. Analyses are now being performed to identify newly methylated basic amino acids produced as a result of enzymatic catalysis by arginine methyltransferase.

Despite its frequent unresponsiveness to currently available treatment, CEM appears to be cmerging into the investigative arena of nucleic acids, basic nucleoproteins, and their intimate relationship to methylating enzymes, especially vitamin $B_{12}$ methyltransferase that is belicved to be involved in the biosynthesis of DNA via the action of folate (Herbert, 1971), and arginine methyltransferase. Whether or not a 'vitamin' will be found for CEM as Dameshek originally prophesied (Dameshek, 1958 ) remains to be determined. Yet it would appear that many of the pathophysiological and pathogenetic factors in this mysterious and often preleukaemic erythroid disorder are beginning to be better understood.

\section{ACKNOWLEDGMENTS}

Supported by the Loyal V. Reynolds Memorial Grant for Cancer Research of the American Cancer Socicty (PDT-13A), and American Cancer Society Grant CH 65-B.

LAWRENCE KASS

Department of Internal Medicine (Simpson Memorial Institute),

The University of Michigan, Amn Arbor, Michigan 


\section{REFERENCES}

BAxter, C.S. \& Byvoet, P. (1974) Effects of carcinogens and other agents on histone methylation by a histone arginine methyltransferase purified from rat liver cytoplasm. Cancer Research, 34, I4I8.

Bendetti, G. (1939) L'eritremia cronica (considerazioni su di un caso typico di mielosi aneritremica cronica. Haematologica, 19, 229.

Bessis, M. (1973) Living Blood Cells and their Ultrastructure. Springer, New York.

Bessis, M., Dreyfus, J., Breton-Gorius, J. \& Sultan, C. (1969) Etude au microscope electronique de onze cas d'anemies refractaires avec enzymopathies multiples. Nouvelle Revue Française d'Hématologie, 9, 87.

Björkman, S.E. (I956) Chronic refractory anemia with sideroblastic bone marrow. A study of four cases. Blood, II, 2 5o.

BlaCk, M.M. \& Ansley, H.R. (1965) Antigen-induced changes in lymphoid cell histones. I. Thymus. Journal of Cell Biology, 26, 201.

Copelli, M. (I912) Di una emopatia sistemizzata rappresentata da una iperplasia eritroblastica (eritromatosis). Pathologica, 4, 460.

Dacie, J.V. \& Mollin, D.L. (1966) Siderocytes, sideroblasts, and sideroblastic anaemia. Acta Medica Scandinavica, 445, Suppl. 179, 237.

Dacie, J.V., Smith, M.D., White, J.C. \& Mollin, D.L. (1959) Refractory normoblastic anaemia. A clinical and haematological study of seven cases. British Journal of Haemarology, 5, 56.

Dameshek, W. (I958) Pernicious anemia, megaloblastosis, and the DiGuglielmo syndrome. Blood, I3, I085.

Dameshek, W. (1965) Sideroblastic anaemia: Is this a malignancy? British Journal of Haematology, II, $\$ 2$.

DamesheK, W. (1969) The DiGuglielmo syndrome. Blood, 34, 567 .

Dameshek, W. \& Baldini, M. (1958) The DiGugliclmo syndrome. Blood, 13, 192.

DiGugluelmo, G. (1923) L'eritremie acuta. Communicazione al XXIX Congresso di Medicina Interna tenuto in Roma dal 24 al Ottobre del 1923. Stabilimento Tipigrafico N. Jovene.

DiGuglielmo, G. (1926) Eritremie acute. Bollettino della Societd Medico-Chirurgica di Pavia, N.S. I, 665.

DiGuglifimo, G. (1928) Le Eritremic. Hacmatologica, 9, 301 .

Digugliflmo, G. \& Quntrrin, N. (1942) Mielosi eritremica cronica. Haematologica, 24, I.

Dörmer, P., Hegemann, F. \& Brinkman, W. (1976) Proliferation and production of hemopoietic cells in two stages of disease: preleukemia and overt leukemia. Klinische Wochenschrift, 54, $46 \mathrm{r}$.

DUESBERG, R. (1940) Anacmien infolge erythroblasticher Fehldifferenzierung. Klinische Wochenschrifi, 19, 417 .
Fisher, R. \& Schmalzi, F. (1964) Uber die Hemmbarkeit der Esteraseaktivitat in blutmonocyten durch Natriun fluorid. Klinische Wochenschrift, 42, 751.

Gunz, F. \& BaIkIE, A.G. (1974) Lenkemia, 3rd edn. Grune \& Stratton, New York.

Hailmbyer, L., Keiderling, W., Bilger, R. \& Bernauer, $H$. (1958) Uber chronische refraktare Anamien mit sideroblastichem Knochenmark (Anemia refractoria sideroblastica). Folia Hacmatologica (Frankfurt), 2, 49.

HeILMEYER, L. \& SChöner, W. (194I) Die chronische reine Erythroblastose des Erwachsenen als Leukaemie-paraller Prozess des erythrocytaren Systems. Deutsches Archiv für Klinische Medizin, 187, 225.

HerberT, V. (1971) Recent developments in cobalamin metabolism. The Cobalamins (ed. by H. R. V. Arnstein and R. J. Wrighton), $p$ 2. ChurchillLivingstone, Edinburgh.

Israeis, M.C.G. \& Wilkinson, J.F. (1936) Achrestic anaemia. Quarterly Journal of Medicine, 5, 69.

KAss, L. (1972) Demonstration of histones in proerythroblasts in pernicious anemia and the DiGuglielmo syndrome. Journal of Histochemistry and Cytochemistry, 20, 8I7.

Kass, L. (1973a) Erythroid histones in chronic erythremic myclosis. Proceedings of the Socicty for Experimental Biology and Medicine, 144, 887.

Kass, L. (1973b) Nuclear 'speckling' in thrombotic thrombocytopenic purpura proerythroblasts. American Journal of Clinical Patholog $\gamma, 59,869$.

KASs, L. (1974a) Methylated arginines in erychremic myclosis. Proceedings of the Socicty for Experimental Biology and Medicine, 145, 944.

Kass, L. (1974b) Metachromatic staining of basic nucleoproteins in chronic erythremic myelosis. Proceedings of the Society for Experimental Biology and Medicine, 62, $2 \mathrm{I}$.

KAss, L. (1974c) Demonstration of histonasc with flavianic acid. Journal of Histochemistry and Cytochemistry, 22, 1159.

KAss, L. (1975a) Cytochemical abnormalities of atypical erythroblasts in acute erythremic myelosis. Acta Haematologica, 54, 321.

KAss, L. (1975b) Rapid detection of ringed sideroblasts in erythremic myelosis. Archives of Parhology, 99, 225.

KAss, L. (1976) Specific esterase activity in erythroleukemia. American Journal of Clinical Parhology (in press).

KAss, L. \& Boroush, M.A. (1976) Methyltetrahydrofolate-dependent methyltransferasc activity in chronic erythremic myelosis and other types of anemias. Biochimica et Biophysica Acta, 437, 639 .

Kass, L. \& Gray, R.H. (1975) Ultrastructural localization of histones in chronic erythremic myelosis. American Journal of Pathology, 81, 493. 
KAss, L. \& HADI, M.Z. (1975) Phosphorylase activity in chronic erythremic myelosis. American Journal of Clinical Pathology, 64, 503.

Kass, L. \& Peters, C. (1976) Nonspecific esterase activity in chronic erythremic myelosis and pernicious anemia. American Journal of Clinical Pathology (in press).

Kass, L., Peters, C. \& Toler, L. (1976) S-Methyltetrahydrofolate-homocysteine cobalamin methyltransferase activity in chronic erythremic myelosis. (Submitted for publication.)

Kass, L. \& Schnitzer, B. (1974) Cytochemical demonstration of histonase activity in human leukocytes. Jourmal of Histochemistry and Cytochemistry, 22, 46.

Kass, L. \& Schnitzer, B. (1975) Refractory Anemia. Thomas, Springfield, Ill.

Kaye, A.M. \& Sheratzky, D. (1969) Methylation of protein (histone) in vitra: enzymatic activity from the soluble fraction of rat organs. Biochimica et Biophysica Acta, 190, 527.

Kushner, J.P., Lee, G.R., Wintrobe, M.M. \& CARTwright, G.E. (1971) Idiopathic refractory sideroblastic anemia. Clinical and laboratory investigation of 17 patients and review of the litcraturc. Medicine, 50, 139.

MCCiure, P.D., Thaler, M.M. \& Cohen, P.E. (1965) Chronic erythroleukemia with chromosome mosaicism. Archives of Internal Medicine, 115, 697.

NeCheles, T.F. \& Dameshek, W. (1967) The DiGuglielmo syndrome: studies in hemoglobin synthesis. Blood, 29, 550.

PAIK, W.K. \& Kim, S. (1969) Enzymatic methylation of histones. Archives of Biochemistry and Biophysics, 134, 632 .

Quagilino, D. \& Hayhoe, F.G.J.(1960) Periodic-acidSchiff positivity in erythroblasts with special reference to DiGuglichmo's disease. Brirish Journal of Haematology, 6, 26.

Rastrick, J.M., Fitzgerald, P.H. \& Gunz, F.W. (1968) Direct evidence for the presence of the ' $\mathrm{Ph}$ ' chromosome in erythroid cells. British Medical Journal, $\mathbf{i}, 96$.

RoBbins, E. \& Borun, T.W. (1967) The cytoplasmic synthesis of histone in HeLa cells and its temporal relationship to DNA replication. Procedings of the
National Academy of Sciences of the United States of America, 57, 409.

Rozenszajn, L., Leibovich, M., Shoham, D. \& Epstein, J. (1968) The esterase activity in megaloblasts, leukaemic and normal haematopoietic cells. British Journal of Haematology, 14, 605.

SanRni, M.I. \& Linman, J.W. (I973) Preleukemia: the hematologic syndrome preceding acute leukemia. American Journal of Medicine, 55, 38.

Sauer, H-J., Wilms, K., Wilmans, W. \& Jaenickes, L. (1973) Die aktivitat der methionin-synthetase (5-methyl-5,6,7,8-tetrahydrofolsaure-homocystein methyltransferase) als proliferations-parameter in wachsenden zellen. Acta Haematologica, 49, 200.

Schnitzer, B. \& KAss, L. (1973) Refractory sideroblastic anemia (chronic erythremic myelosis). An ultrastructural study of the bone marrow. American Journal of Clinical Pathology, 60, 343.

Sexauer, J., Kass, L. \& Schnitzer, B. (1974) Subacute myelomonocytic leukemia. Clinical, morphologic and ultrastructural studies of to cases. American Journal of Medicine, 57, 853 .

Steiner, J., Baldini, M. \& Dameshek, W. (1963) Heme synthesis defect in 'refractory' anemias with ineffective erythropoiesis. Blood, 22, 8 ro.

Swanson, C.P. (1974) Cellular Physiology. PrenticeHall, New York.

Taylor, R.T., Hanna, M.L. \& Hutton, J.J. (1974) 5-Methyltetrahydrofolate homocysteine cobalamin methyltransferase in human bone marrow and its relationship to pernicious anemia. Archives of Biochemistry and Biophysics, 165, 787.

Valentine, W.N., Konrad, P.N. \& Paglia, D.E. (1973) Dyserythropoiesis, refractory anemia, and 'pre-leukenia'; metabolic features of the erythrocytes. Blood, 4 I, 857.

VAVRA, J.D. \& Poff, S.S. (1967) Heme and porphyrin synthesis in sideroblastic anemia. Journal of Laboratory and Clinical Medicine, 69, 904.

Wickramsinghe, S.N., Chalmers, D.G. \& Cooper, E.H. (I968) A study of ineffective erythropoiesis in sideroblastic anaemia and erythraemic myelosis. Cell and Tissue Kinetics, I, 43.

YaM, L.T., LI, C.Y. \& CrosBy, W.H. (197I) Cytochemical identification of monocytes and granulocytcs. American Journal of Clinical Palhology, 55, 283. 